DIW BERLIN

Discussion

Papers

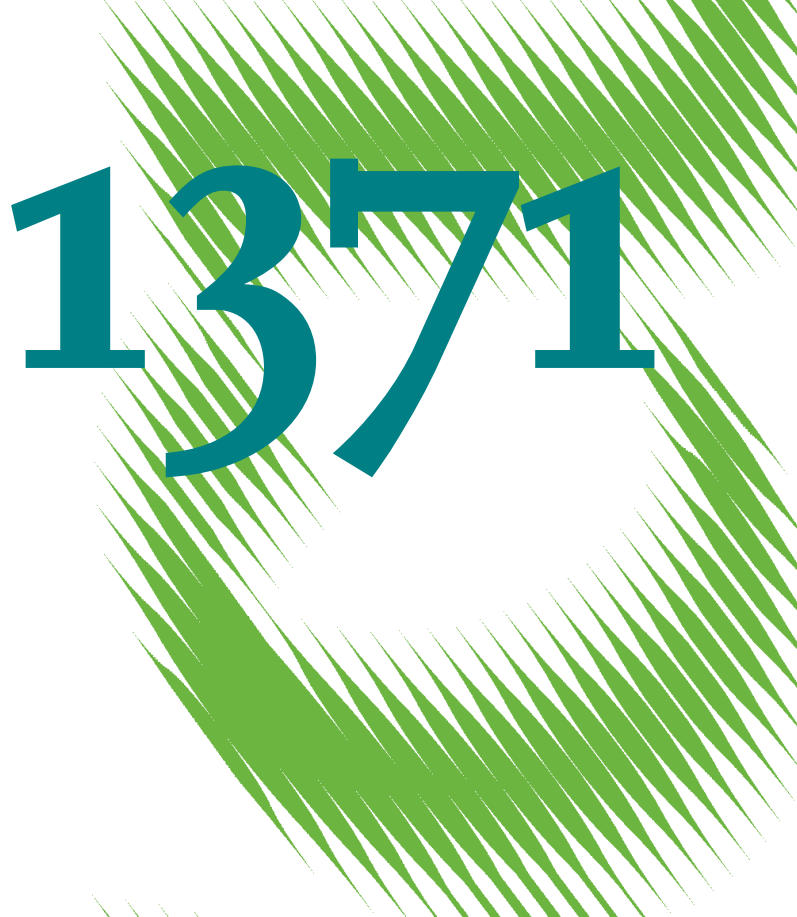

Regulation, Innovation and Technology Diffusion

Evidence from Building Energy Efficiency Standards in Germany 
Opinions expressed in this paper are those of the author(s) and do not necessarily reflect views of the institute.

IMPRESSUM

(C) DIW Berlin, 2014

DIW Berlin

German Institute for Economic Research

Mohrenstr. 58

10117 Berlin

Tel. $+49(30) 89789-0$

Fax +49 (30) $89789-200$

http://www.diw.de

ISSN print edition $1433-0210$

ISSN electronic edition 1619-4535

Papers can be downloaded free of charge from the DIW Berlin website:

http://www.diw.de/discussionpapers

Discussion Papers of DIW Berlin are indexed in RePEc and SSRN:

http://ideas.repec.org/s/diw/diwwpp.html

http://www.ssrn.com/link/DIW-Berlin-German-Inst-Econ-Res.html 


\title{
Regulation, Innovation and Technology Diffusion - Evidence from Building Energy Efficiency Standards in Germany
}

\author{
Makram El-Shagi* Claus Michelsen ${ }^{\dagger}$ \\ Sebastian Rosenschon ${ }^{\ddagger}$
}

March 27, 2014

\begin{abstract}
The impact of environmental regulation on technology diffusion and innovations is studied using a unique data set of German residential buildings. We analyze how energy efficiency regulations, in terms of minimum standards, affects energy-use in newly constructed buildings and how it induces innovation in the residential-building industry. The data used consists of a large sample of German apartment houses built between 1950 and 2005. Based on this information, we determine their real energy requirements from energy performance certificates and energy billing information. We develop a new measure for regulation intensity and apply a panel-error-correction regression model to energy requirements of low and high quality housing. Our findings suggest that regulation significantly impacts technology adoption in low quality housing. This, in turn, induces improvements in the high quality segment where innovators respond to market signals.
\end{abstract}

JEL Codes: D2, Q4, R5

Keywords: environmental regulation, innovation, technology diffusion, residential real estate, energy efficiency

\footnotetext{
${ }^{*}$ California State University Long Beach, 1250 Bellflower Blvd, Long Beach, CA, 90840, Halle Institute for Economic Research, University of Mannheim, Email: makram.elshagi@iwh-halle.de

${ }^{\dagger}$ German Institute for Economic Research, Mohrenstr. 58, 10117 Berlin, Email: cmichelsen@diw.de

${ }^{\ddagger}$ Halle Institute for Economic Research, Kleine Maerkerstr. 8, 06108 Halle, Germany, Email: sebastian.rosenschon@iwh-halle.de
} 


\section{Introduction}

Since the March 2011 Fukushima Daiichi nuclear disaster, politicians are paying increased attention to sustainability, resource and energy efficiency issues. Many countries are seeking to restructure their energy supply systems and stimulate energy efficiency investments. In this context, residential housing plays an important role, since, according to OECD-data, it accounts for up to $40 \%$ of final energy needs in developed countries. The lion's share of residential energy demand stems from heating and cooling. In the US this constitutes for about half of all residential energy demand. In Europe even two-thirds of residential energy demand is for heating and cooling (OECD 2003). Politicians in the European Union (EU) are especially focused on the potential savings in the real estate sector and are seeking to implement the "Nearly Zero-Energy Buildings" (NZEB) standard by the end of 2020. Numerous policy measures and initiatives are being introduced in order to achieve this goal. Building energy codes are probably the oldest and most frequently used instrument designed to increase the energy efficiency of real estate (Jacobsen \& Kotchen 2013, Annunziata et al. 2013, Iwaro \& Mwasha 2010). In this context, politicians often emphasize the twofold importance of such regulations: First, to reduce actual energy requirements and to encourage investors to adopt existing energy efficiency technologies and, second, to create incentives to develop new innovative technologies for future modifications of energy efficiency standards (see Saheb et al. 2013, European Commission \& European Parliament 2012).

While building energy codes are generally assumed to be effective in reducing energy requirements, empirical knowledge on their actual impact is relatively scarce. As pointed out by Jacobsen \& Kotchen (2013), empirical assessment is important for several reasons. First, the effectiveness of regulation crucially depends on the real level of energy requirements. If regulation is not tight enough, construction industry's good building practice will remain unaffected. Second, actual energy savings often lag far behind engineers' promises (Metcalf \& Hassett 1999, Michelsen \& Müller-Michelsen 2010, Schröder et al. 2009, Brounen et al. 2012) due to either technical flaws or end-user behavior that partly offsets the increased technical energy efficiency of housing (Sunikka-Blank \& Galvin 2012). Thus, engineers' calculations do not necessarily reflect real energy (cost) savings, which are the actual measures of interest for investors and policy-makers. Indeed, the few empirical studies available indicate that a energy efficiency regulation is an effective instrument to increase the real energy performance of newly constructed buildings.

In the early 1990s, the idea to stimulate innovation by environmental regulation entered the political arena. This approach goes back to the well received articles by Porter (1991) and Porter \& Van der Linde (1995). In a nutshell, the so called "Porter Hypothesis" states that environmental regulation can result in Pareto-optimal outcomes. While effectively protecting the environment, regulation creates incentives to innovate and thereby increase the competitiveness of firms and the economy (Ambec et al. 2013). In this context, the various empirical studies do not provide clear cut evidence. It remains unclear whether regulation positively impacts economic performance and innovative capacities of firms, industries or regions. In particular, almost no empirically insights exist on the potential incentives of building energy codes to design new, innovative and less heating energy demanding buildings. The specific studies available 
are small in number and all use qualitative methodologies (see Beerepoot \& Beerepoot 2007, Gann et al. 1998, Vermeulen \& Hovens 2006).

In the present study, we address this gap in the empirical literature and explicitly assess whether environmental regulation drives innovation in the residential building sector. Specifically, the analysis adds to the existing findings around building energy codes by taking a differentiated, longitudinal perspective on the diffusion/ adoption of existing technologies and the market uptake of new innovations. Thereby, we are the first to include a measure for real regulatory intensity. Our inquiry also contributes to the more general and still controversial discussion around the "Porter Hypothesis", particularly by providing longitudinal evidence, which is frequently missing from the debate (Ambec et al. 2013).

Moreover, the construction and residential real estate sector can be seen as an interesting test case for the impact of regulation in general. The sector is large (e.g. the German construction sector accounts for about $11 \%$ of total GDP) and covers a wide range of services, crafts and branches in industrial manufacturing. In particular, the construction industry is not concentrated and is highly competitive (Buzzelli \& Harris 2003) - this makes us believe that the pressure and incentives to innovate are spread out along the supply chain.

In our analysis, we assess the energy consumption of a large number of German apartment houses, built since 1950 under a variety of regulatory regimes. Incorporating the time dimension allows us to model the effects of regulatory intensity, measured as the share of houses affected by the regulation in the last year prior to its introduction, on the energy performance of buildings. Moreover, the longitudinal perspective allows us to disentangle the effects of regulatory interventions on technology diffusion (the adoption of existing energy saving technologies) and innovation in the house building industry. To do so, we analyze the effects of regulation on different quality segments in a panel framework, borrowing from quantile regression method.

The remainder of the paper is structured as follows. Section 2 reviews the relevant literature on the effectiveness of energy efficiency standards in residential real estate and introduces the basic ideas behind the "Porter Hypothesis". Section 3 introduces our data and presents some stylized facts on energy efficiency in German residential housing. The model is outlined in Section 4 and the results are discussed in Section 5. Section 6 concludes.

\section{Related literature}

\subsection{Empirical evidence on the effectiveness of building en- ergy codes}

As pointed out by Jacobsen \& Kotchen (2013), there are few empirical studies on the real energy saving effects of building codes in the real estate sector. For a long time, it was generally claimed that adequate data, especially to analyze the supply side of housing, was not available (Olsen 1987, Dipasquale 1999, Gyourko 2009, Eichholtz et al. 2011). This has changed with the availability of new micro-data sources, e.g. data on environmental certification like Energy Star ${ }^{\circledR}$. The first studies on building energy codes, based on detailed micro-data gathered from consumption bills, were published starting in 2012 . 
The first paper to use energy billing information is Jacobsen \& Kotchen (2013). The sample consists of 2,239 homes in Gainesville, Florida, in the US. Based on this data, the authors evaluate the effects of the 2002 modified state wide energy building code. Monthly electricity and gas bills for the period of 1999-2005 serve as basis for a twofold empirical strategy, consisting of (i) a set of linear regressions to test whether level effects can be identified on average and in a seasonal perspective; and (ii) a difference-in-difference approach to analyze the performance of regulated vs. unregulated dwellings. While controlling for observable housing characteristics and heating degree days, the authors conclude that building energy codes are an effective instrument for reducing energy consumption in residential real estate. Moreover, they find that, in the case of the Florida state regulation, engineer's calculations and empirical observations are almost identical.

Another micro-data based study, Koirala et al. (2013), analyzes the effects of adopting the "International Energy Conservation Code" (IECC) in the US. The study combines an impressive amount of housing records (containing energy performance measures, housing attributes and individual information on residents) collected from the American Community Survey (the sample consists of $1 \%$ of US residences) with aggregate data on regulation, heating degree days and energy prices on the state level. They find that the application of IECC allows households to save about $1.8 \%$ on electricity, $1.3 \%$ on natural gas, and $2.8 \%$ on heating oil compared to dwellings in states without this regulation.

Evidence from outside the US is presented by Michelsen \& Rosenschon (2012). They analyze the effects of German regulation from a long term perspective, 1967 to 2006, using energy billing information for a sample of 41,496 apartment houses. Standardized energy consumption of explicitly non-refurbished homes is modeled as a function of building characteristics, spatial controls and, most importantly, housings' age interacted with dummies for the regulation regime at the time of construction. They find evidence for two effects of tighter building codes: first and in line with the findings of Jacobsen \& Kotchen (2013), the authors present level effects in energy consumption induced by changes in the legal setting. Secondly, they find regulation regime specific differences in energy consumption over time, which they interpret as differing trends in technological progress.

Other studies use aggregate information from US states to assess the impact of regulation. Aroonruengsawat et al. (2012) find significant effects of energy efficiency standards in US states based on panel data analysis. They conclude that regulation decreased electricity consumption by up to $5 \%$ in states with high construction activity. Deason \& Hobbs (2011) demonstrate, based on a set of panel regressions, that building codes decreased residential primary energy consumption by $1.3 \%$ compared to states without regulation. In the first and frequently cited study on the impact of regulation, Jaffe \& Stavins (1995) conclude that building codes did not affect observed building practice. Moreover, the adoption of energy efficiency measures is not affected by regulation. 


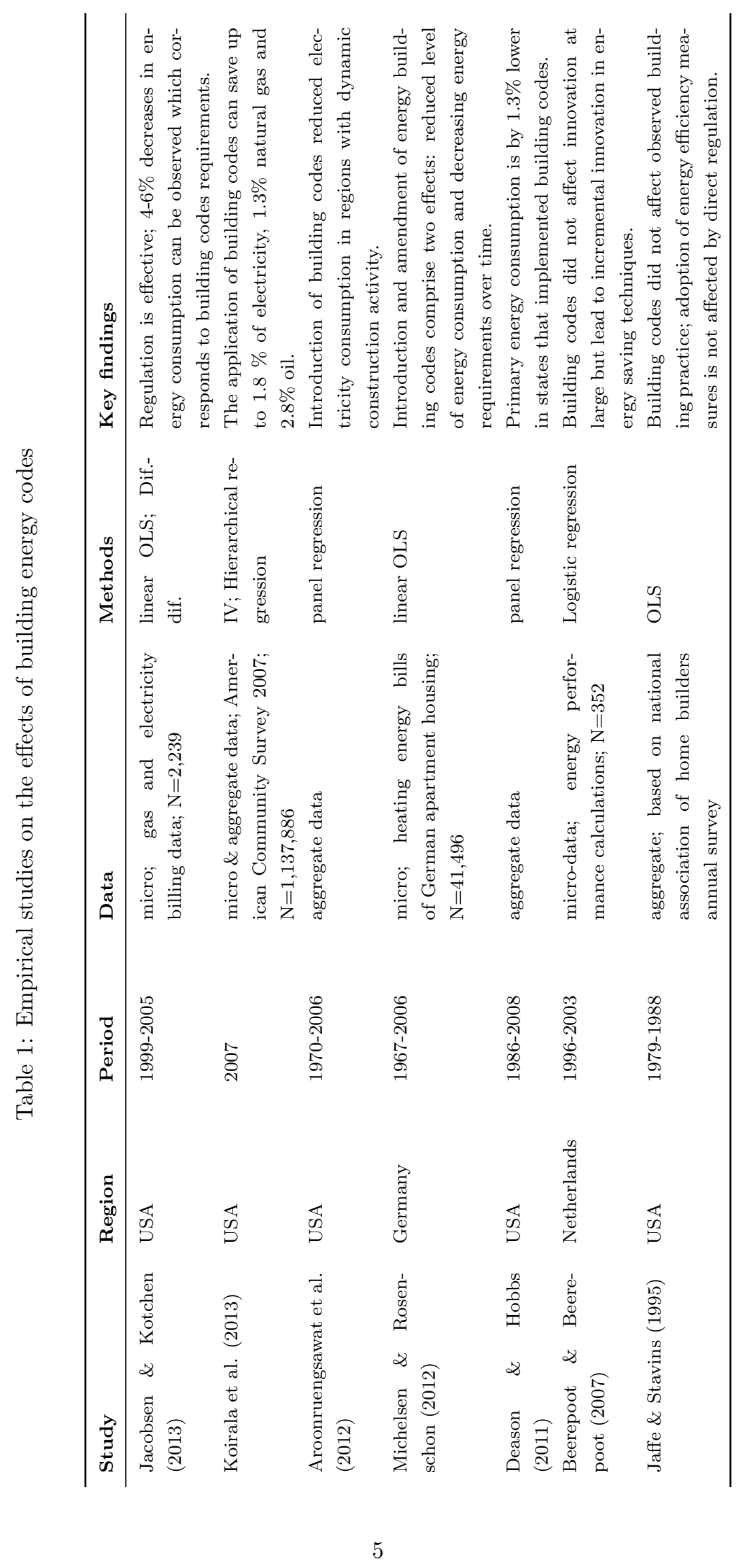




\subsection{Evidence for the "Porter Hypothesis" in the house- building sector}

The "Porter Hypothesis" claims that, if adequately designed, regulation signals "resource inefficiencies and potential technological improvements," increases "corporate awareness," reduces "the uncertainty that investments to address the environment will be valuable," creates "pressure that motivates innovation and progress," and levels "the transitional playing field. During the transition period to innovation-based solutions, regulation ensures that one company cannot opportunistically gain position by avoiding environmental investments" (Porter \& Van der Linde 1995, p. 100). All these factors can favor innovation activities and, ideally, result in better economic performances of firms as well as increased competitiveness of the economy as a whole. In the literature three forms of the Porter Hypothesis are discussed (see figure 1): the "weak" form links regulation to innovation activities. On the firm as well as the aggregate level, R\&D expenditures or patenting activities are often used to proxy innovation effort (e.g. Jaffe \& Palmer 1997). The "strong" version assumes that regulation increases firms' competitiveness. Most studies in this context analyze productivity data of industries and branches (for a review of the literature see Jaffe \& Stavins 1995, Alpay et al. 2002). The "narrow" definitions states that flexible regulatory policies give firms greater incentives to innovate. However, empirical tests for this type of relationship are difficult (Lanoie et al. 2011).

Figure 1: The causality chain of the porter hypothesis

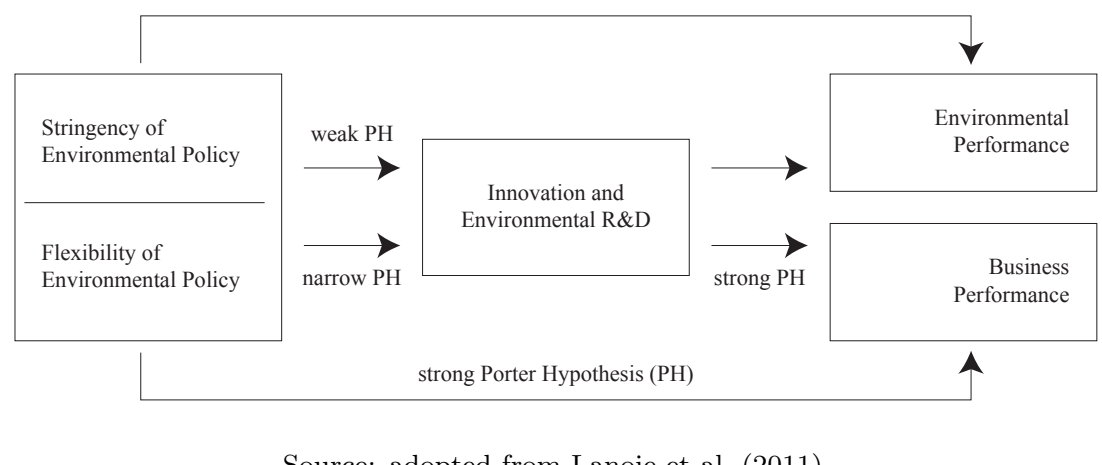

Source: adopted from Lanoie et al. (2011)

For the construction sector, few studies deal with the question of whether environmental regulation, i.e. building energy codes, affect innovation activity. Beerepoot \& Beerepoot (2007) analyze the impact of building codes on new technology development. They analyze this question against the background of the Dutch residential building industry's innovation system. They assess a small sample of Dutch housing records and conclude that regulation does not provide sufficient incentives to create really new innovations. However, the authors argue that standards at least induce some incremental energy efficiency improvements in the Netherlands.

Based on 35 Dutch commercial office building projects Vermeulen \& Hovens (2006) analyze the diffusion of 'mature' and the uptake of 'young' innovations. 
They find that 'young' innovations, in addition to other factors, are adopted because they were needed in order for the projects to comply with the Dutch Energy Performance Standards (EPS). Based on the additional finding that EPS did not increase the adoption rates of 'mature' innovations, the authors conclude that, "the instrument of Energy Performance Standards will, at best, be effective if it is regularly made more stringent and if it addresses more recently emerging appliances" (Vermeulen \& Hovens 2006, p. 2735).

Gann et al. (1998) analyzed the British "Building Regulation Part L, Conservation of Fuel and Power." Based on 21 expert interviews, the authors discuss various channels how regulation enters the innovations process in the housebuilding sector. Overall, Gann et al. (1998) find evidence that the shift from a "prescriptive" regulatory regime (in terms of allowed construction materials and techniques) to a "performance-based" approach increased innovation activities, which provides indirect support for the strong "Porter Hypothesis."

In summary, knowledge on the effectiveness of building energy codes and the incentives that such regulation creates to innovate can be characterized as being far from comprehensive. The consensus appears to be that, in general, building codes, by accelerating the adoption of energy efficiency measures, decrease energy consumption in the housing sector. But in absence of longitudinal studies almost nothing can be said about regulatory intensity. Existing literature focuses largely on the mere introduction, not the amendment of energy efficiency regulation over time. This is an important limitation of studies centered on addressing the question of whether environmental regulation stimulates innovation, i.e. the uptake of heating energy saving materials and building designs. We address these issues in a novel approach by explicitly considering regulatory intensity of building energy codes as explanatory variable of energy requirements of newly constructed buildings. Moreover, we disentangle potential effects for the groups of "technology adopters" in the low quality housing market segment and "innovators" at the high end of housing quality. This allows us to draw findings on the effectiveness of building energy codes for the diffusion of existing technologies, the uptake of new innovations (the "weak" form of the Porter Hypothesis) and, moreover, on the interaction of both aspects.

\section{Empirical strategy, data and stylized facts}

In line with the available studies on the energy performance of real estate, our analysis is based on the assessment of micro-data on real energy consumption gathered from energy performance certificates and energy billing information. We use similar data as Michelsen \& Rosenschon (2012), but follow a different empirical approach. In contrast to Michelsen \& Rosenschon (2012), who use the full set of German apartment houses to model the average energy requirement per year of construction under different regulatory regimes, our approach is to focus on the tails of the distribution, the $10^{t h}$ and $90^{t h}$ percentiles of the energy coefficients. We use this information to proxy the energy performance in the low quality market segment $\left(90^{\text {th }}\right.$ percentile - where energy efficiency is low) and the $10^{\text {th }}$ percentile, the high quality segment. Investors in the low quality segment are forced to adopt more efficient technologies when regulation is effectively tightened. Thus, regulation might promote the market diffusion of energy efficiency technologies. In the high quality segment, however, regulation 
does not necessarily affect investor plans. Changes in the energy performance over time can be interpreted as a result of innovation, which might be an indirect result of regulation, as suggested by the "Porter Hypothesis."

\subsection{Housing data}

micro-data At first glance the empirical data suggests that the energy performance of apartment buildings in Germany has increased substantially since the middle of the 20th century. The distribution of energy coefficients in our sample is illustrated in Figure 2. We observe a general decline in both the upper and lower percentiles of energy coefficients over time, indicating both technological progress in terms of energy efficiency and adoption/ market diffusion of the existing technologies. The median house build in 2007 has an energy performance roughly identical to the most energy efficient houses built 40 years earlier. That is, when it comes to fostering energy efficiency, creating incentives to adopt seems to matter more than creating incentives improve potential energy efficiency through innovation.

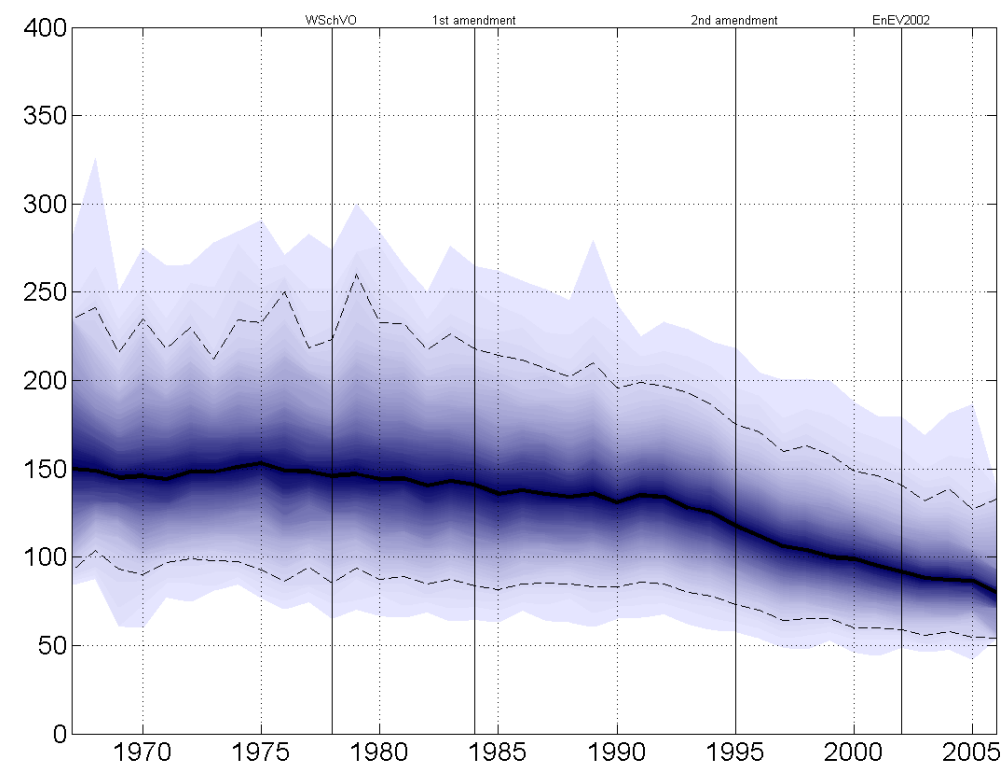

Figure 2: Distribution of energy coefficients by year of construction

The energy coefficients, as used in our sample, are computed based on a three year average of real energy consumption per square meter living space. To ensure comparability across observations, energy consumption is adjusted by climatic parameters that reflect differences in local as well as inter-temporal climatic and weather conditions. ${ }^{1}$ Since energy requirements (in the type of

\footnotetext{
${ }^{1}$ Data is provided by one of the leading energy billing service providers, ista Germany $\mathrm{GmbH}$. Our sample contains approximately 300,000 apartment houses in Germany, which covers about $15 \%$ of the total apartment housing market. The procedure for climatic adjustment
} 
houses analyzed in our sample) have a natural lower bound, the distribution has a positive skew for any construction year. Also, while energy efficiency improves, the gap between the most efficient and the most inefficient houses narrows over time.

The aim of this study is to identify the development of building standards under different regulatory regimes. Since we rely on real energy consumption today rather than engineers' assessment to evaluate the energy performance of buildings, ex post changes in housing quality, i.e. refurbishment of the facilities must be ruled out. ${ }^{2}$ To ensure this, we use information on the refurbishment status for the five most important construction parts of a house (from the energy efficiency perspective): roof, facade, windows, basement ceiling and heating system. The energy certificates in our sample contain information whether these building parts have been refurbished or replaced within the past 15 years, more than 15 years ago, if they are non-refurbished or if the status is unknown. Observations are only included in the analysis if it was reported as being "non-refurbished" in all five construction parts. In total, our sample comprises of approximately 40,000 observations. Further, the energy certificates contain information on the year of construction, the location of the building (ZIP-code district), the fuel type, the size of the apartment house measured in square meter of living space and the number of apartments.

\subsection{Regulation regimes and regulation intensity}

Housing regulation in Germany In Germany building codes have a relatively long tradition of being used as a policy instrument to affect energy efficiency standards (Geller et al. 2006). The first, the "Heat Insulation Ordinance" (WSchV), came into force in November 1977. In the light of the first oil crisis in the early 1970 s, politicians decided to define minimum standards for the energy efficiency for both residential and commercial buildings. Based on so called U-values, measures for the thermal conductivity of construction parts, the regulation defined an aggregate maximum level of annual $(a)$ energy requirement of 250 kilowatt-hours (kWh) per square meter living space $\left(\mathrm{m}^{2}\right)$ for newly constructed homes. This regulation was amended twice, in 1984 and 1995. In 2002 WSchV was replaced with the "Energy Saving Ordinance" (EnEV), which is still in force.

The basis for regulation, however, changed over time. While WSchV was introduced against the background of strategic trade policy (i.e. to reduce the dependency on fossil fuel imports), EnEV was developed in response to sustainability issues and concerns about global warming (Geller et al. 2006, p. 567f). Since 2002, the EnEV has been amended twice: 2009 and 2013. The recent change in regulation is also associated with a switch in the guidance

follows the official guidelines for calculating energy performance certificates, as implemented in Germanys "energy saving ordinance" of 2009 (EnEV 2009). This procedure standardizes energy requirements to the German city of "Würzburg" in the year 2000. Thus, there is no need to control for heating degree days, as applied in many other studies. Further, the three year average of energy consumption ensures to some extend that individuals' behavior does not significantly bias the energy performance measure.

${ }^{2}$ Although some studies control for refurbishment and find substantial effects (e.g. Brounen et al. (2012) or Leth-Petersen \& Togeby (2001)), other studies do not consider refurbishment in their analysis of vintage class specific energy performance of real estate (e.g. Costa \& Kahn (2011) or Chong (2012)). 
Table 2: Regulatory steps of energy building codes in Germany: 1978-2021

\begin{tabular}{rlr}
\hline year & regulation & max. $k w h / m^{2} a$ \\
\hline until 1978 & no regulation & $\infty \mathrm{kWh}$ \\
1978 & Heat Insulation Ordiance (WSchV) & $250 \mathrm{kWh}$ \\
1984 & amendment of WSchV & $230 \mathrm{kWh}$ \\
1995 & amendment of WSchV & $150 \mathrm{kWh}$ \\
2002 & Energy Saving Ordinance (EnEV) & $100 \mathrm{kWh}$ \\
2009 & amendment of EnEV & $60 \mathrm{kWh}$ \\
2016 & amendment of EnEV & $45 \mathrm{kWh}$ \\
2021 & amendment of EnEV & $0 \mathrm{kWh}$ \\
\hline
\end{tabular}

regime: while previous building codes were issued without stating exact validity periods and without information on further regulatory steps, EnEV 2013 is the first that outlines a stepwise tightening of construction law to a carbon neutral standard by 2021 .

Table 3: Panel structure

\begin{tabular}{ll}
\hline Regions (N) & Time Span $(\mathbf{T})$ \\
\hline Lower Saxony & $1950-2005$ \\
North Rhine-Westphalia & $1950-2005$ \\
Baden-Wuerttemberg & $1950-2005$ \\
Bavaria & $1950-2005$ \\
Berlin & $1990-2005$ \\
North & $1950-2005$ \\
Rhine-Hesse & $1950-2005$ \\
East & $1990-2005$ \\
\hline N=8 & \\
T=56 & \\
Obs.=368 & \\
\hline
\end{tabular}

Panel data The sample analyzed in this paper covers apartment houses constructed between 1950 and 2005. With this sample, we are able to observe energy coefficients of buildings constructed under five different regulatory regimes - ranging from unregulated buildings until the end of 1977 to EnEV 2002 standards. As Germany was divided until 1990, we drop all apartment houses constructed under GDR housing market regulation (built before 1990 and located in Saxony, Thuringia, Saxony-Anhalt, Brandenburg, Berlin and Mecklenburg-West Pomerania) to ensure identical institutional settings. To the extent possible, our regions coincide with the German federal states (Länder). However, to generate sufficiently large entities where the percentiles of the empirical distributions in our sample are meaningful approximations of the entire population, smaller Länder are combined to larger units. Hamburg, Bremen and Schleswig-Holstein form the "North" region, the Saarland, Rhineland-Palatinate and Hesse form 
Rhine-Hesse, and the former GDR Länder of Brandenburg, Mecklenburg-West Pomerania, Saxony, Saxony-Anhalt, and Thuringia form the "East" group (see Figure 3).

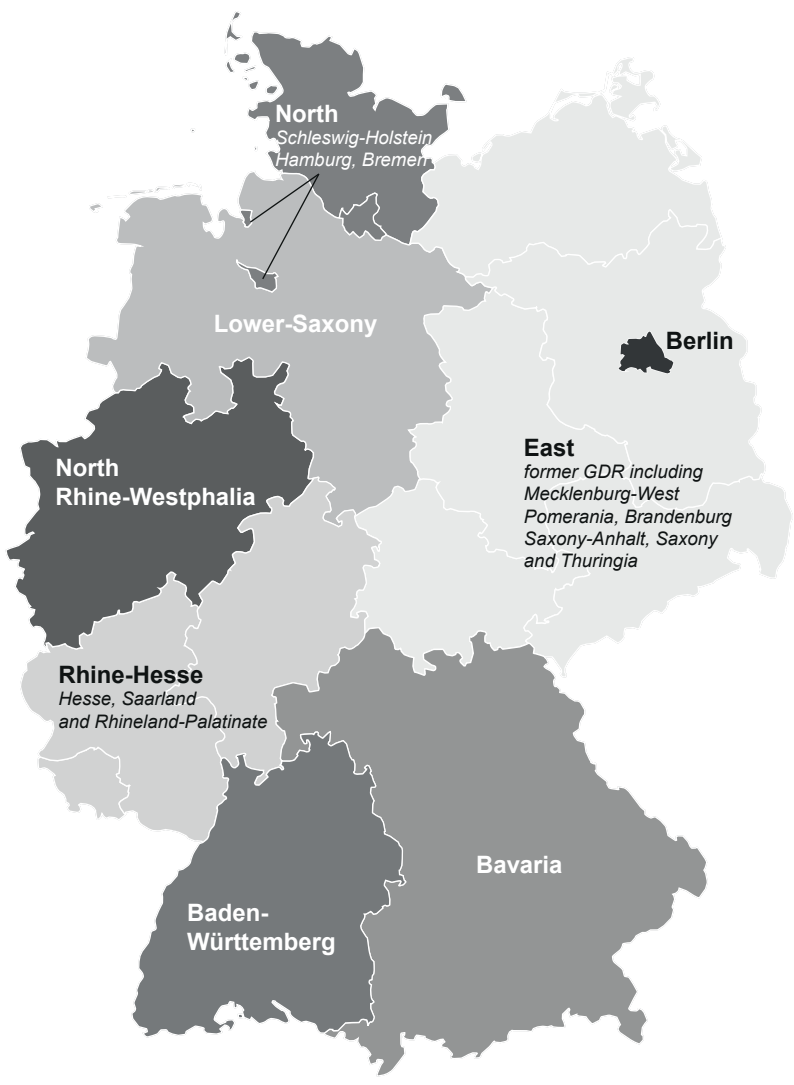

Figure 3: Regions

We generate separate innovation and adaptation time series for each region, defined as the $10^{\text {th }}$ and the $90^{\text {th }}$ percentile of energy coefficients for houses of a specific year of construction in the respective region. Variables controlling for the attributes of the housing stock are computed as region/year mean values of the corresponding building features.

Measuring regulation intensity Instead of capturing regulation through a set of shift and slope dummies, as in most of the previous literature, we aim to actually measure regulation intensity in the present study. However, using the level of regulation itself (in terms of maximum allowed energy requirements) is difficult for a number of reasons. First, because energy building codes are amended over time, regulation is instationary by construction. Since economic reasoning suggests a relation between the level of regulation and the level of energy efficiency, this could not be solved by simply taking first differences, but requires some error correction type of indicator. Concerning energy regulation this, however, creates a new set of problems. Regulation is supposed to affect the behavior of economic agents, if it is binding to at least some agents, but 
is not supposed to be neutral when irrelevant for every agent. In econometric terms this type of phenomenon is commonly treated using regime switching models. Both commonly used versions are problematic in our case. When using the difference between the maximum of the empirical distribution and the regulation level as indicator, we can use the sign of this error correction term as a plausible regime indicator in a model with deterministic regime switching. This indicator turns negative whenever a regulation does not affect any agent. However, this induces further noise into the model since this indicator is strongly affected by outliers. Using a more stable indicator, such as the difference between the median of the empirical distribution and regulation, requires an endogenous identification of regimes as done in threshold or Markov switching models. However, these models also come at the cost of substantial uncertainty, since regimes are often only weakly identified. To overcome these issues we borrow from quantile regression and propose to use a regulation index $r$ at time $t$ that is defined as the share $F$ of houses built in $t-1$ that would have been affected by the regulation $R$ relevant at time $t$ :

$$
r_{t}=F_{H(t-1)}\left(R_{t}\right),
$$

where $H(t)$ is the set of houses build at time $t . R$ is scaled in $k W h /\left(m^{2} a\right) . r_{t}$ indicates immediately when any agent is affected by regulation, while not being prone to outliers.

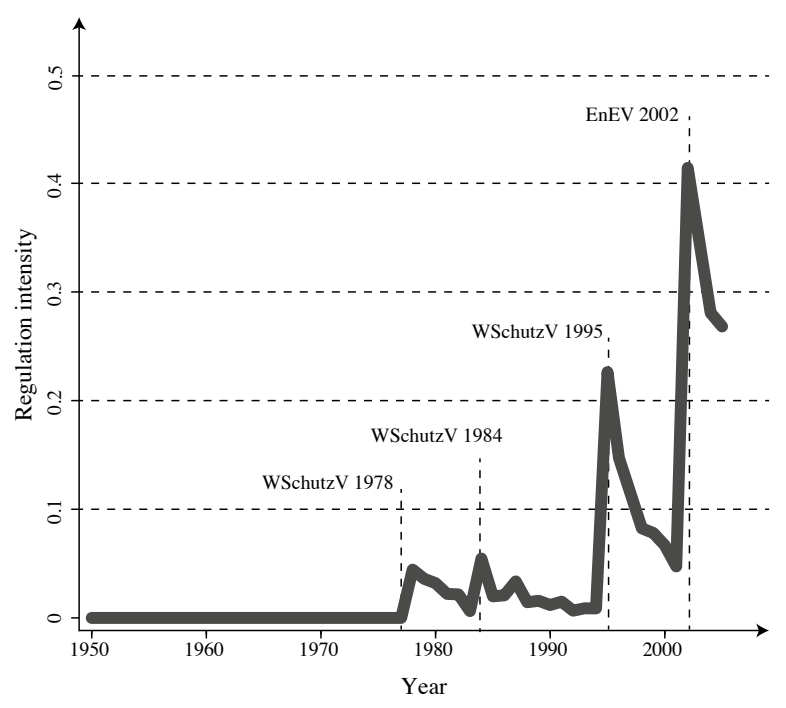

Figure 4: Regulation intensity

\subsection{Macroeconomic, attitudinal and other control vari- ables}

Energy prices Energy prices are proven to be important predictors for the energy performance of buildings. As Costa \& Kahn (2011) demonstrate for residential housing in the USA, electricity prices at the time of construction 
determine to a large extent current heating energy needs. For the German case, the most important heating fuels are oil and natural gas. As implemented in long-term cross-border delivery contracts, the price of gas is to some extent tied to oil. Therefore, we include the oil price as a proxy for heating energy costs. One might argue that forward looking agents consider price expectations rather than the past energy price development when deciding on long term investments (such as real estate) (Quigley 1984, Nesbakken 2001), however, most institutional oil price forecasts are essentially flat (in real terms), taking past movements of the oil price as granted. Therefore, we account for lagged changes in the logged oil price measured as the US Dollar price of Brent crude oil (free on board).

Green attitude There are several studies on green technology diffusion addressing the roles of behavior and "green" attitudes, e.g. in the decision to adopt an innovative energy efficient heating system. It is frequently found that people who perceive environmental issues to be important are more likely to adopt environmentally friendly technologies and, moreover, have a greater willingness to pay for such technologies (Michelsen \& Madlener 2012, Claudy et al. 2011). To differentiate whether it is truly the regulation that matters, or a generally more supportive attitude towards "green" ideas in society that might also be highly correlated to ecologically motivated regulation, we control for green support in the population using opinion polls. In the context of "green" buildings, this measure is also used by Brounen \& Kok (2011). Our attitude control is based on a monthly, representative political survey conducted by "Forschungsgruppe Wahlen" to forecast German parliamentary elections. We include the first difference of vote shares for the green party differentiated by year and region to our estimations. As the Green party was found in January 1980, information on green support is only available from the survey since 1979. We assume a vote share of 0 for the respective earlier years.

Spatial controls Studies address the role of local market conditions on real estate investor's decisions to adopt energy efficient technologies. Kok et al. (2012, p.562), for example, find that, for the case of green office space, "the diffusion has been more rapid in metropolitan areas with higher incomes, and in those with sound property market fundamentals...." In general, compared to rural areas, economic conditions tend to be better in urbanized agglomerations. To capture this effect, we control for urbanized housing markets including the share of apartments in our sample that is located in or the direct surrounding of a town with at least 50,000 inhabitants. Additionally, we include time fixed effects for each region as described in section 3.1. 


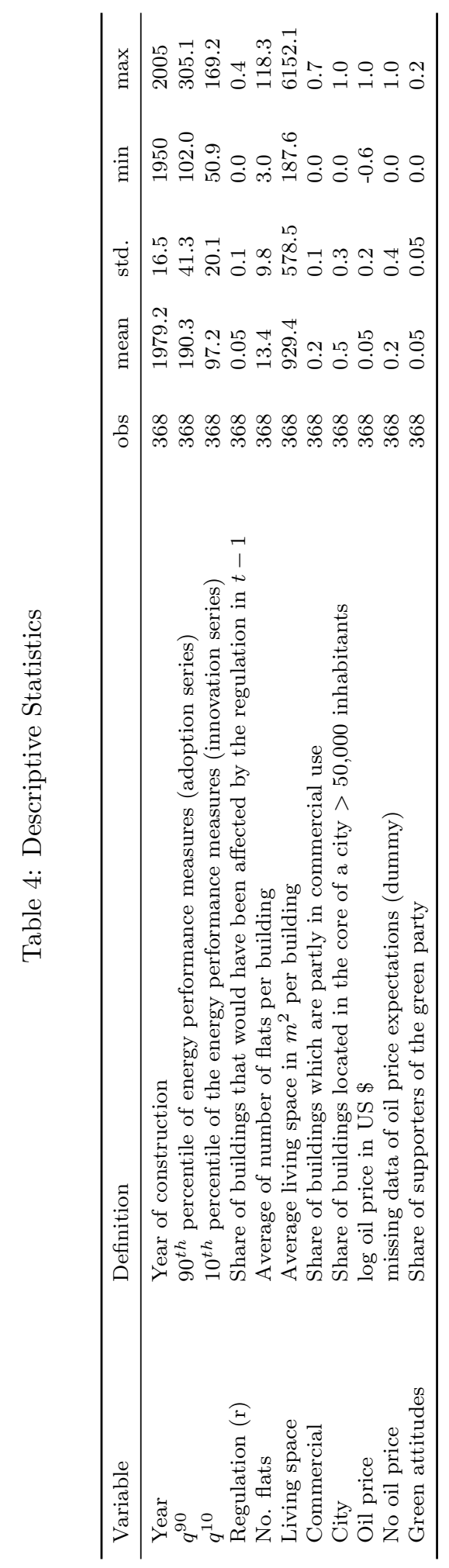


Building characteristics The building size affects housing's "natural" energy efficiency due to differences in the ratio between interior space and the outer shell of a building. As for example demonstrated by Leth-Petersen \& Togeby (2001) for Danish apartment blocks, the smaller the house, the higher are energy requirements. We control for size including the average living space in $m^{2}$ and the average number of flats per building. Further, we include the share of buildings used for residential as well as commercial purposes.

\section{Model and methods}

\subsection{Estimation}

Model setup Our panel setup essentially is an error correction type model taking the form:

$$
\begin{array}{r}
\Delta q_{j, t}^{90}=\alpha_{1}+\alpha_{2}\left(q_{t-1}^{90}-q_{t-1}^{10}\right)+\alpha_{3} \Delta q_{j, t-1}^{90}+\alpha_{4} \Delta q_{j, t-1}^{10} \\
+\alpha_{5} r_{t}+\sum_{m=1}^{M} \psi_{m} \bar{c}_{j, t}^{m}+\sum_{k=1}^{M} \phi_{k} C_{k} \\
\Delta q_{j, t}^{10}=\beta_{1}+\beta_{2}\left(q_{t-1}^{90}-q_{t-1}^{10}\right)+\beta_{3} \Delta q_{j, t-1}^{90}+\beta_{4} \Delta q_{j, t-1}^{10} \\
+\beta_{5} r_{t}+\sum_{m=1}^{M} \xi_{m} \bar{c}_{j, t}^{m}+\sum_{k=1}^{M} \chi_{k} C_{k},
\end{array}
$$

where $q_{j, t}^{p}$ is the natural logarithm of the $p^{t h}$ percentile of the energy performance measures of buildings in region $j$ constructed in year $t, \bar{c}_{j, t}^{m}$ is the mean of the building specific control variable $c^{m}$ for region $j$ and year of construction $t$, and $C_{k}$ are non construction specific control variables. Essentially, this model is a version of a panel cointegration model, where the cointegration relation is restricted to one. An unrestricted version of the model has been tested and yields similar results. The key difference between our approach and conventional panel cointegration models is the use of an error correction term relying on the entire sample rather than the specific region. Thereby, we avoid carrying the uncertainty in the quantile estimates in regions with few observations into the error correction term.

The wild bootstrap To account for heteroscedasticity, the estimation is made using an adjusted wild bootstrap (Wu 1986). When resampling for a wild bootstrap, the original residuals are multiplied with a factor $v$ drawn from a distribution that guarantees that the moments of the distributions of $\varepsilon$ and $\varepsilon v$ resemble each other. Most importantly, mean and variance should be identical for $\varepsilon$ and $\varepsilon v$. Contrary to the residual bootstrap the wild bootstrap maintains fluctuations of variance over time from the original sample.

Following Davidson \& MacKinnon (2010), we apply the same multiplier $v$ to residuals from both equations, allowing cross equation correlation similar to SUR estimation approaches. Similarly, we apply the same $v$ to observations in the same period, thereby accounting for cross sectional correlation in the residuals. This leaves us with a fairly low number of possibilities to resample. To allow a large number of distinct bootstrap samples (and thereby prevent 
statistical artifacts in the results), we draw the multipliers from Webb's six point distribution (Webb 2013) instead of the more commonly used two-point distributions proposed by Mammen (1993) and Davidson \& Flachaire (2008).

Generated regressor problem An additional advantage of using a bootstrap in our application is that it simultaneously accounts for the generated regressor problem that occurs since our measures for adaptation and innovation are quantile estimates based on the available subsample. Since the entire process is simulated in our bootstrap, resampling the endogenous variable implies resampling the lagged endogenous that is used as predetermined explanatory variable at the same time. Since the measurement error in the left hand side variable is a (substantial) part of the error term, this measurement error is automatically considered by the bootstrap with respect to the lagged endogenous, which is our only variable where a generated regressor problem matters.

However, as a robustness test, we also apply a two step bootstrap where we explicitly consider the uncertainty in the quantile estimates. To do so, we resample the micro-data before aggregating to the panel level before each iteration of our wild bootstrap. For each state and year specific subsample we draw (with replacement) $N_{i, t}$ buildings from the original corresponding subset of the micro-data. This resampled micro-data is used to create a new panel dataset. Equation 3 is estimated based on that data. The coefficients and residuals obtained thereby are then used for a single wild bootstrap iteration. Since the uncertainty coming from the estimation of quantiles from our sample is accounted for twice in this procedure, the standard errors of the coefficients are larger when applying the double bootstrap by construction. However, all results remain stable quantitatively and mostly significant, also at lower significance level.

\subsection{Deriving impulse response functions}

Since our sample includes periods without regulation, we cannot capture the impact of regulation through the level of regulation itself but instead rely on the regulation index proposed in Section 3.2. Contrary to regulation that might be treated as exogenous, the regulation index is merely predetermined since it includes past information on the distribution of energy coefficients. While this is sufficient for the estimation of unbiased regression coefficients, it poses a problem when computing impulse response functions where changes of the regulation index due to changes in energy efficiency have to be treated as endogenous.

For the impulse responses presented in Section 5 we assume that energy coefficients at any point in time are normally distributed. If this assumption holds, the two points of the distribution considered in our estimation, i.e. the $10^{\text {th }}$ and the $90^{\text {th }}$ percentile, describe the entire distribution of energy coefficients for a given year. That is, we can compute share of houses affected by the regulation for any given period endogenously.

Following Fry \& Pagan (2007) we do not report the median impulse response function, but the individual impulse response (generated by the bootstrap) that is closest to the median. This guarantees that the IRF as reported is actually consistent with a potential parameter constellation. 


\section{Results}

Our estimations confirm the general finding of the previous literature that regulation successfully affects energy efficiency rather than merely reinforcing developments already initiated by private actors. However, it sheds some new light on the propagation of regulation throughout the economy. We find that regulation strongly affects the adoption of existing technologies in the low quality housing market segment (see table 6). This result is not surprising since in general regulatory compliance is high in Germany, indicated for example by Transparency International's "Corruption Perceptions Index."

Table 5: Model diagnostics

\begin{tabular}{lll}
\hline & F-Statistic & R-Squared \\
\hline $\begin{array}{l}\text { Model 1: Adoption of energy effi- } \\
\text { ciency }\left(90^{t h} \text { percentile }\right)\end{array}$ & $13.44^{* * *}(\mathrm{~N}=352, \mathrm{DF}=18,333)$ & 0.4209 \\
$\begin{array}{l}\text { Model 2: Innovations in energy ef- } \\
\text { ficiency }\left(10^{t h} \text { Percentile }\right)\end{array}$ & $8.203^{* * *}(\mathrm{~N}=352, \mathrm{DF}=18,333)$ & 0.3072 \\
\hline
\end{tabular}

However, the results for the $10^{\text {th }}$ percentile show an entirely different picture: we find no direct impact of regulation on the energy performance of innovators. At the same time, we find a strongly positive impact of the error correction term, i.e. the spread between the considered time series. That is, the impact of regulation on innovation that has been found in the micro-data, is entirely of an indirect nature. Regulation reinforces the incentive to adopt existing technologies, thereby reducing the spread between adopters and innovators. The reduction of the spread - or in other words: the shrinking technological advantage of the innovators over adopters - is, in turn, fostering innovation.

Figure 5 shows the joint dynamics of innovation and adaption in both percentage changes and accumulated level changes after the introduction of higher energy standards that affect $50 \%$ of the current construction. While the effect on adaption is spread over several years (with a significantly negative impulse response function over almost a decade) the vast majority of the impact happens right after the introduction of the regulation. Surprisingly innovators do not react at all in the first year. Starting two years after the new energy standards were established, the energy coefficients of the innovators start to decrease, maintaining a highly improved speed of innovation for two decades. After 20 years, energy consumption in both the low and high quality housing market segments is almost $20 \%$ below the level where it would have been without the new energy standard. 
Percentage change of energy efficiency over time
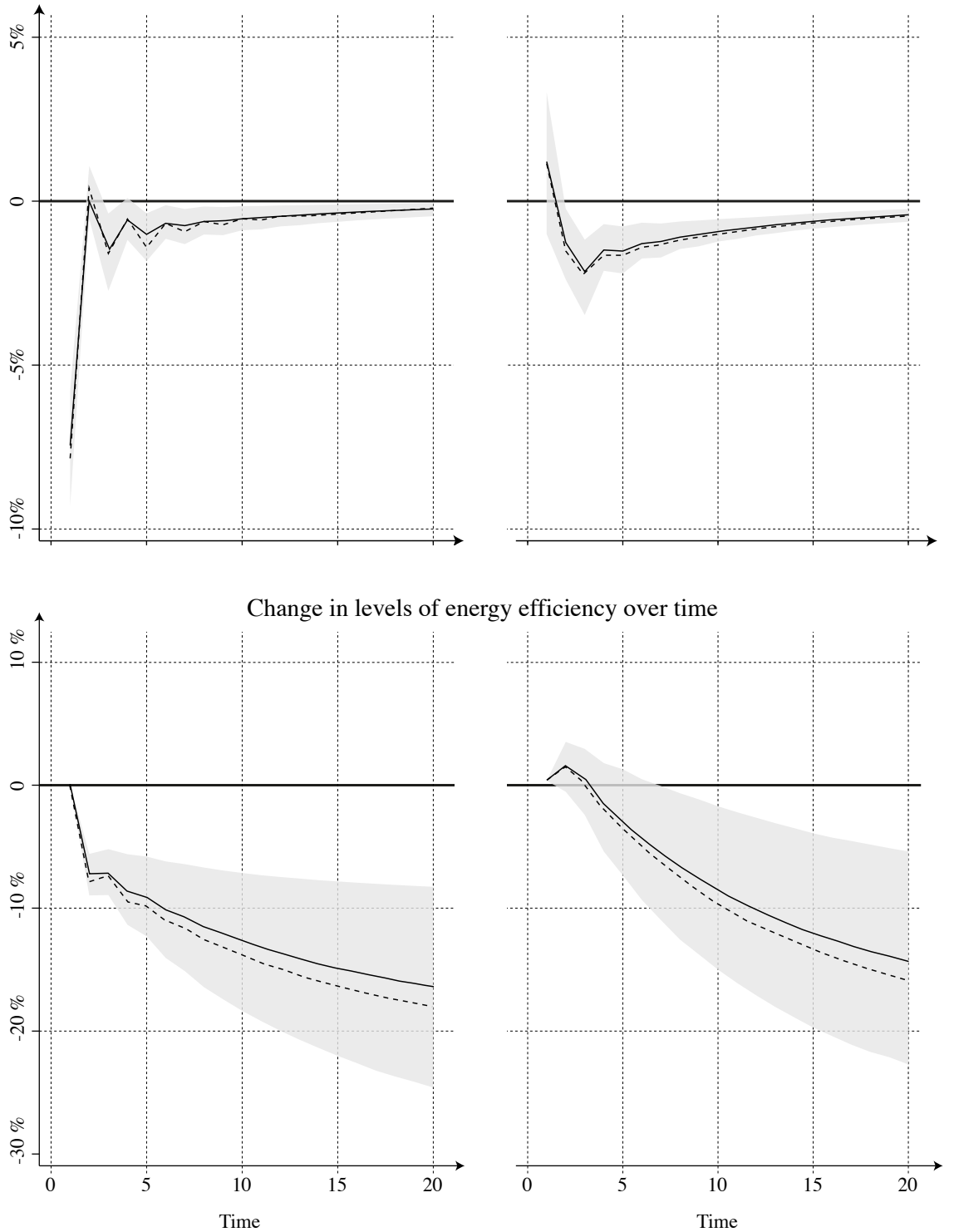

standard deviation

bootstrapped IRF estimated IRF

Figure 5: Impulse response to regulation 


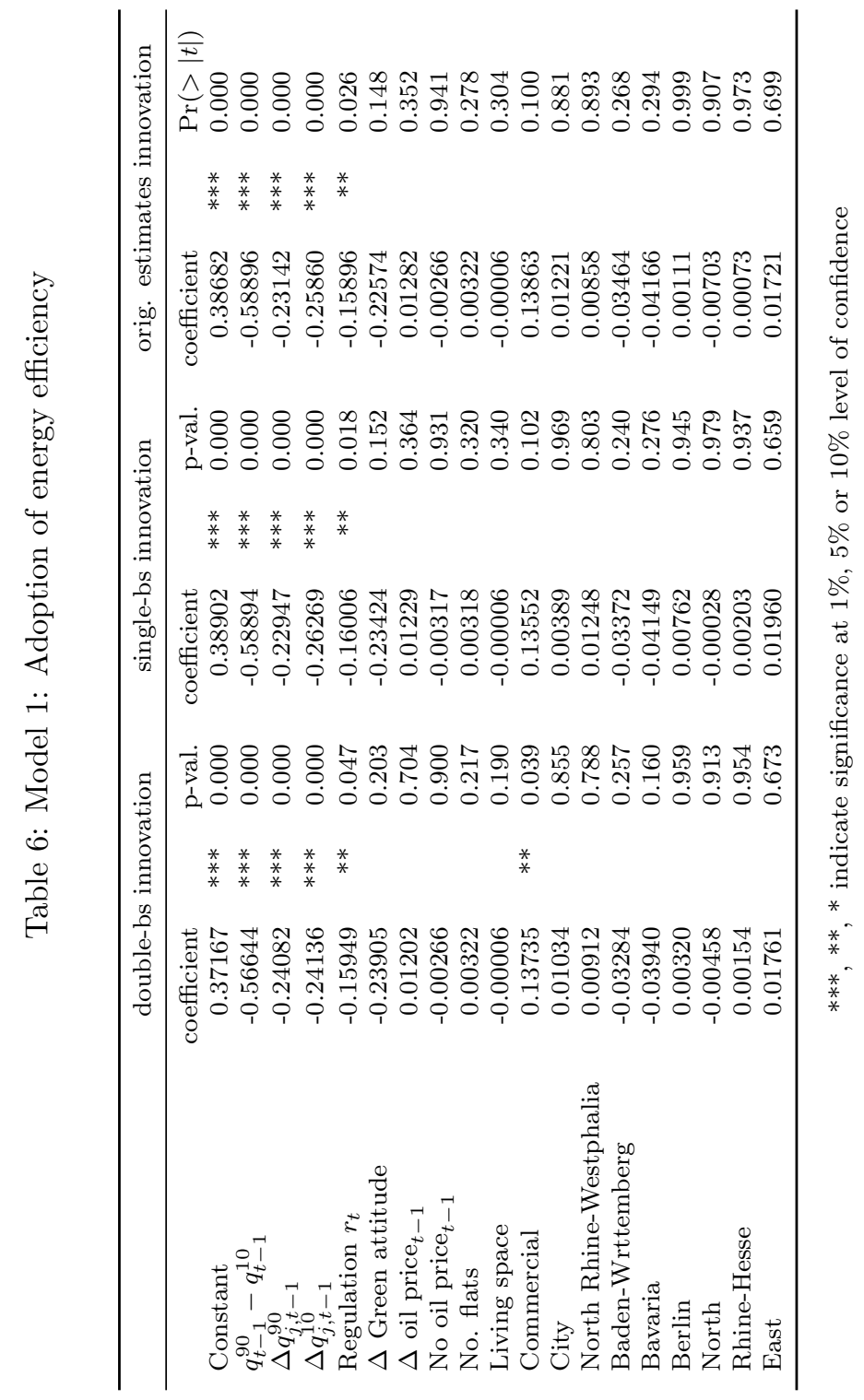




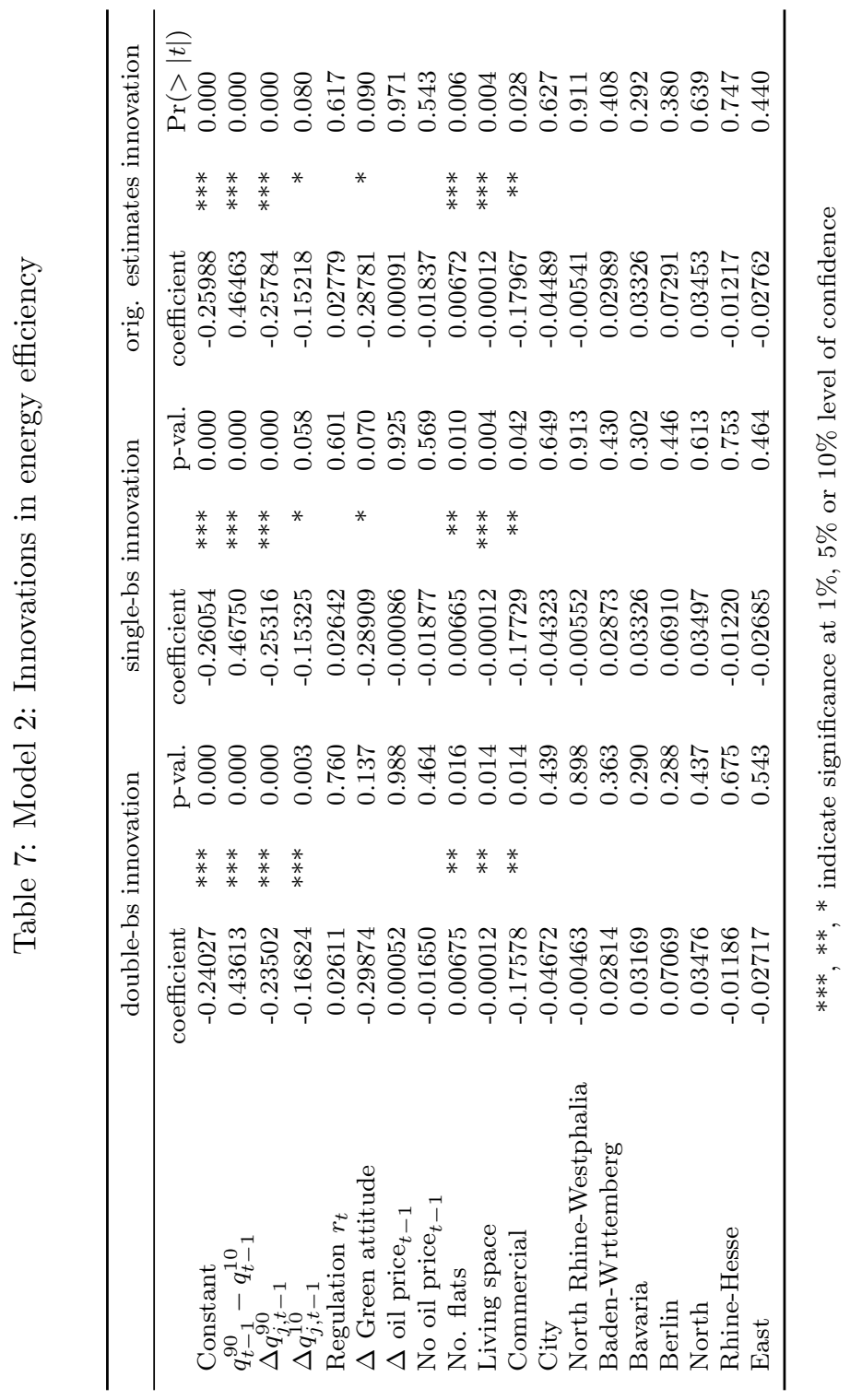


Since the regulation considered in our study works through fixed limits rather than incentives that scale with the energy efficiency, the results meet the theoretical expectations. Only investors who build less energy inefficient housing have an immediate incentive to adapt their behavior, thus reducing the risk of an apartment house construction permit not being approved by the authorities. This stimulates the market diffusion of construction techniques, building designs and materials fostering energy efficiency. The indirect effect on innovation is also intuitively traceable. As "innovators" are not directly affected by regulation, they most likely respond to market signals - thus after the introduction of new energy efficiency standards. This is also consistent with the "Porter Hypothesis" that states that a more favorable environment for innovation is created by new regulation.

All our results hold when controlling for oil price changes or lagged oil price changes as a proxy of energy price movements and green attitude. Oil prices are not significant in neither the adaption nor the innovation equations, which contrasts with the findings of previous studies on housing quality in the USA. In this context, it must be noted that residential real estate in the US is, in most cases, owner occupied. We analyze apartment housing in Germany, of which roughly $80 \%$ are rental segment. There is an ongoing discussion about the incentives to invest in energy efficiency, since landlords bear the costs of investment but cannot typically pass the costs on to the tenants who benefit from reduced energy bills. In the literature this is referred to as the so-called "landlord tenant dilemma" (Stull 1978, Rehdanz 2007) and might serve as an explanation for the observations in this study.

The share of green voters, albeit having a sizable coefficient, is only significant in the innovation equation and even there only at the $10 \%$ level. Quantitatively the coefficients of green attitude in both equations are very similar. The coefficients bear the expected negative sign. However, these estimates might downplay the role of green attitudes in the change of energy efficiency. The volatility of green voting might be much higher than the volatility of the underlying attitudes.

\section{Conclusions}

The present paper evaluates the effects of building energy codes in the German apartment housing sector. Based on our analysis, we can draw two main conclusions:

i) In line with previous studies, we find that energy building codes effectively decrease energy requirements in residential real estate. More precisely, energy efficiency standards successfully affect technology adoption in the low quality housing market segment. Our results show that regulatory intensity is important in this context; the tighter the regulation, the higher the technology adoption and the faster the diffusion of existing technologies in the low quality housing market segment.

ii) Regulation has no direct impact on "innovators." However, there is a strong indirect effect of regulation on innovation. Investors in the high end housing market segment strongly react to a narrowing technology gap compared to adopters, even if their own performance is far from being in risk of 
being affected by regulation in the near future. Although this effect is merely indirect, the strong overall importance of regulation for innovation essentially constitutes an empirical validation of the "weak" form of the "Porter hypothesis."

Unfortunately, the methodology applied does not allow for exact conclusions about the communication channels between the housing market segments. But the indirect link between regulation and innovation favors explanations that emphasize shifts in production technology or the importance of market trends. A new energy efficiency framework might motivate real estate investors in the high quality segment to readjust their 'signaling' of outstanding quality to tenants; for example by developing less heating energy demanding buildings. At the same time, the improvement in general energy efficiency increases the credibility of the imminent threat of more rigid future regulation. Both aspects are associated with a higher demand for energy efficiency innovations. Alternatively, the manufacturing processes might increase efficiency as a result of scale economies in production; cost reductions potentially allow for the market-uptake of previously economically non-feasible inventions. Altogether these factors increase the incentives for innovation. However, a detailed analysis should be subject to future research.

At first glance, our results seem to encourage the application of building energy codes in general. Policy makers, however, should read the presented insights carefully. Although we find that past policy has been effective, this does not necessarily imply that this success can be improved upon with future rounds of regulation. In the German case, for example, regulation is already very tight, narrowing the room for future regulatory interventions. Applying our results to the announced regulatory steps in 2014 and 2016 an - in terms of $k W h /\left(m^{2} \cdot a\right)$ - only small indirect impact on energy efficiency in the innovative segment can be expected. Moreover, it must be noted that our analysis did not evaluate the "optimal" level of regulatory intensity. Thus, policy makers should take into account drawbacks on aggregate construction activity. This potentially decelerates technology diffusion and innovation, which in turn might offset the positive effects from regulation.

Over all regulation seems to be a valid policy option in countries with relatively poor housing quality, i.e. high energy requirements. For countries like Germany, the impact of regulation is less important. Especially against the background of the targeted NZEB housing standard by 2020, other activities to stimulate energy efficiency investments and energy efficiency innovations must supplement the legal setting. In this context, the results on "green attitude" provide an alternative option to speed up innovation. Rising awareness for energy saving technologies and communicating the positive effects of energy efficiency can be one such supplemental strategy. 


\section{References}

Alpay, E., Kerkvliet, J. \& Buccola, S. (2002). Productivity growth and environmental regulation in mexican and us food manufacturing, American Journal of Agricultural Economics 84(4): 887-901.

Ambec, S., Cohen, M. A., Elgie, S. \& Lanoie, P. (2013). The Porter Hypothesis at 20: Can Environmental Regulation Enhance Innovation and Competitiveness?, Review of Environmental Economics and Policy 7(1): 2-22.

Annunziata, E., Frey, M. \& Rizzi, F. (2013). Towards nearly zero-energy buildings: The state-of-art of national regulations in Europe, Energy (in Press).

Aroonruengsawat, A., Auffhammer, M. \& Sanstad, A. H. (2012). The Impact of State Level Building Codes on Residential Electricity Consumption, The Energy Journal 33(1): 31-52.

Beerepoot, M. \& Beerepoot, N. (2007). Government regulation as an impetus for innovation: Evidence from energy performance regulation in the Dutch residential building sector, Energy Policy 35(10): 4812-4825.

Brounen, D. \& Kok, N. (2011). On the economics of energy labels in the housing market, Journal of Environmental Economics and Management 62(2): 166179.

Brounen, D., Kok, N. \& Quigley, J. M. (2012). Residential energy use and conservation: Economics and demographics, European Economic Review 56(5): 931-945.

Buzzelli, M. \& Harris, R. (2003). Small is Transient: Housebuilding Firms in Ontario, Canada 1978-98, Housing Studies 18(3): 369-386.

Chong, H. (2012). Building vintage and electricity use: Old homes use less electricity in hot weather, European Economic Review 56(5): 906-930.

Claudy, M. C., Michelsen, C. \& O'Driscoll, A. (2011). The diffusion of microgeneration technologies - assessing the influence of perceived product characteristics on home owners' willingness to pay, Energy Policy 39(3): 14591469.

Costa, D. L. \& Kahn, M. E. (2011). Electricity consumption and durable housing: understanding cohort effects, American Economic Review: Papers 8 Proceedings 101(3): 88-92.

Davidson, R. \& Flachaire, E. (2008). The wild bootstrap, tamed at last, Journal of Econometrics 146(1): 162-169.

Davidson, R. \& MacKinnon, J. G. (2010). Wild bootstrap tests for iv regression, Journal of Business 8 Economic Statistics 28(1).

Deason, J. \& Hobbs, A. (2011). Codes to cleaner buildings: effectiveness of US Building Energy Codes, A CPI Report Version 1.

Dipasquale, D. (1999). Why don't we know more about housing supply?, Journal of Real Estate Finance and Economics 18(1): 9-23. 
Eichholtz, P., Kok, N. \& Quigley, J. M. (2011). The economics of green building, Review of Economics and Statistics 95(1): 50-63.

European Commission \& European Parliament (2012). Directive 2012/27/eu of the european parliament and of the council of 25 october 2012 on energy efficiency, amending directives 2009/125/ec and 2010/30/ec and repealing directives 2004/8/ec and 2006/32/ec, Official Journal of the European Union 315: 1-56.

Fry, R. \& Pagan, A. (2007). Some Issues in Using Sign Restrictions for Identifying Structural VARs, Working Paper 14, NCER.

Gann, D. M., Wang, Y. \& Hawkins, R. (1998). Do regulations encourage innovation?-the case of energy efficiency in housing, Building Research \& Information 26(5): 280-296.

Geller, H., Harrington, P., Rosenfeld, A. H., Tanishima, S. \& Unander, F. (2006). Polices for increasing energy efficiency: Thirty years of experience in OECD countries, Energy Policy 34(5): 556-573.

Gyourko, J. (2009). Housing Supply, Annual Review of Economics 2009(1): 295-318.

Iwaro, J. \& Mwasha, A. (2010). A review of building energy regulation and policy for energy conservation in developing countries, Energy Policy 38(12): $7744-7755$.

Jacobsen, G. D. \& Kotchen, M. J. (2013). Are Building Codes Effective at Saving Energy? Evidence From Residential Billing Data in Florida, Review of Economics and Statistics 95(1): 34-49.

Jaffe, A. B. \& Palmer, K. (1997). Environmental regulation and innovation: a panel data study, Review of Economics and Statistics 79(4): 610-619.

Jaffe, A. B. \& Stavins, R. N. (1995). Dynamic Incentives of Environmental Regulations: The Effects of Alternative Policy Instruments on Technology Diffusion, Journal of Environmental Economics and Management 29(3): 43-63.

Koirala, B., Bohara, A. \& Li, H. (2013). Effects of energy-efficiency building codes in the energy savings and emissions of carbon dioxide, Environmental Economics and Policy Studies (in Press).

Kok, N., McGraw, M. \& Quigley, J. M. (2012). The diffusion over time and space of energy efficiency in building, The Annals of Regional Science 48(2): 124 .

Lanoie, P., Laurent-Lucchetti, J., Johnstone, N. \& Ambec, S. (2011). Environmental Policy, Innovation and Performance: New Insights on the Porter Hypothesis, Journal of Economics \&3 Management Strategy 20(3): 803-842.

Leth-Petersen, S. \& Togeby, M. (2001). Demand for space heating in apartment blocks: measuring effects of policy measures aiming at reducing energy consumption, Energy Economics 23(4): 387-403. 
Mammen, E. (1993). Bootstrap and wild bootstrap for high dimensional linear models, The Annals of Statistics pp. 255-285.

Metcalf, G. E. \& Hassett, K. (1999). Measuring the Energy Savings from Home Improvement Investments: Evidence from Monthly Billing Data, Review of Economics and Statistics 81(3): 516-528.

Michelsen, C. C. \& Madlener, R. (2012). Homeowners' preferences for adopting innovative residential heating systems: A discrete choice analysis for Germany, Energy Economics 34(5): 1271-1283.

Michelsen, C. \& Müller-Michelsen, S. (2010). Energieeffizienz im Altbau: Werden die Sanierungspotenziale überschätzt? Ergebnisse auf Grundlage des ista-IWH-Energieeffizienzindex, Wirtschaft im Wandel 16(9): 447-455.

Michelsen, C. \& Rosenschon, S. (2012). The Effects of Building Energy Codes in Rental Housing: The German Experience, Economics Bulletin 32(4): 3488 3502 .

Nesbakken, R. (2001). Energy consumption for space heating: a discretecontinuous approach, Scandinavian Journal of Economics 103(1): 165-184.

OECD (2003). Environmentally Sustainable Buildings, Organisation for Economic Co-Operation and Development, Paris.

Olsen, E. O. (1987). The demand and supply of housing service: A critical survey of the empirical literature, Handbook of Regional and Urban Economics 2: $989-1022$.

Porter, M. E. (1991). America's green strategy, Scientific American 264(4): 168.

Porter, M. E. \& Van der Linde, C. (1995). Toward a new conception of the environment-competitiveness relationship, The journal of economic perspectives $\mathbf{9}(4)$ : 97-118.

Quigley, J. M. (1984). The production of housing services and the derived demand for residential energy, Rand Journal of Economics 15(4): 555-567.

Rehdanz, K. (2007). Determinants of residential space heating expenditures in Germany, Energy Economics 29(2): 167-182.

Saheb, Y., Saussay, A., Johnson, C., Blyth, A., Mishra, A. \& Gueret, T. (2013). Modernising Building Energy Codes, IEA \& UNDP.

Schröder, F., Greller, M., Hundt, V., Mundry, B. \& Papert, O. (2009). Universelle Energiekennzahlen für Deutschland- Teil 1: Differenzierte Kennzahlverteilungen nach Energieträger und wärmetechnischem Sanierungsstand, Bauphysik 31(6): 393-402.

Stull, W. J. (1978). The landlord's dilemma : Asking rent strategies in a heterogeneous housing market, Journal of Urban Economics 5(1): 101-115.

Sunikka-Blank, M. \& Galvin, R. (2012). Introducing the prebound effect: the gap between performance and actual energy consumption, Building Research \&3 Information 40(3): 260-273. 
Vermeulen, W. J. V. \& Hovens, J. (2006). Competing explanations for adopting energy innovations for new office buildings, Energy Policy 34(17): 27192735 .

Webb, M. D. (2013). Reworking Wild Bootstrap Based Inference for Clustered Errors.

Wu, C.-F. J. (1986). Jackknife, bootstrap and other resampling methods in regression analysis, The Annals of Statistics 14(4): 1261-1295. 